\title{
Perfil protéico e reconhecimento antigênico de extratos de larvas infectantes (L3) de Wuchereria bancrofti
}

\author{
Proteic profile and antigenic recognition of extracts from \\ Wuchereria bancrofti L3 infective larvae
}

\author{
Janaina Miranda ${ }^{1}$, Amélia Maciel ${ }^{2}$, Renata Maria Costa Souza ${ }^{1}$, André Freire Furtado ${ }^{1}$ \\ e Elizabeth Malagueno ${ }^{3}$
}

\begin{abstract}
RESUM0
A caracterização protéica dos extratos de larvas infectantes (L3) de Wuchereria bancrofti foi realizada por eletroforese em gel de poliacrilamida, em presença de dodecil sulfato de sódio (SDS-PAGE) e o reconhecimento antigênico das proteínas por Western-blot. 0 maior número de bandas protéicas reconhecidas foi evidenciado nos extratos AgSE (105, 100, 76, 55, 49, 39 e $32 \mathrm{kDa})$ e AgS (100, 76, 55, e $49 \mathrm{kDa})$ na presença de soros de indivíduos endêmicos normais. As bandas de 49 e $55 \mathrm{kDa}$ foram reconhecidas pelos soros dos microfilarêmicos, endêmicos normais (residentes de área endêmica livres de infecção filarial) e portadores da forma crônica da doença. As larvas infectantes foram obtidas pela dissecção de mosquitos Culex quinquefasciatus infectados com sangue microfilarêmico de voluntários portadores de microfilaremia, residentes do Município de Olinda-PE. Nos 792 indivíduos investigados pela técnica da gota espessa mensurada ( $60 \mu$ l de sangue) 87 foram positivos (11\%). A diferenca da positividade entre homens e mulheres não foi significativa e a faixa etária de 11 a 19 anos foi a de maior prevalência.
\end{abstract}

Palavras-chaves: Wuchereria bancrofti. Larva infectante. Perfil antigênico.

\begin{abstract}
A study of protein characterization and recognition of the antigenic profile was accomplished in extracts of infective larvae (L3) from Wuchereria bancrofti. Two proteins of relative molecular weight of 49 and $55 \mathrm{kDa}$ were recognized as antigenic in all extracts by the tested sera. The secretory/excretory antigen presented the largest number of recognized bands (105, 100, 76, 55, 49, 39 and $32 \mathrm{kDa})$ followed by the somatic antigen (100, 76, 55 and $49 \mathrm{kDa})$ when incubated with pools of sera from healthy individuals resident in endemic areas (normal endemics). Human sera and parasitized blood used to infect mosquitoes in order to obtain L3, were collected from microfilaraemic individuals living in a filariasis endemic area. From 792 persons screened with the thick smear technique, 87 (11\%) were positive. № statistical significance was observed between genders. The group between 11 and 19 years of age presented higher percentage of infection (36.8\%).
\end{abstract}

Key-words: Wuchereria bancrofti. Infective larvae. Antigenic profile.

A filariose linfática é causada pelo nematóide Wuchereria bancrofti e é transmitida ao homem pelo mosquito Culex quinquefasciatus. A forma evolutiva do parasita de maior importância no contexto imunológico é a larva de terceiro estádio ( L3), pois representa a forma infectante que dissemina a parasitose e o primeiro contato do parasita com o hospedeiro definitivo. Pouco se conhece sobre suas características biológicas, antigênicas, aspectos moleculares e mesmo sobre as relações que se estabelecem entre hospedeiro-parasita, seja homem infectado e Wuchereria bancrofti, seja entre vetor e parasita.

Na falta de um modelo animal experimental, para W. bancrofti, as informações que se possuem sobre a ação de larvas infectantes em seus hospedeiros mamíferos, referem-se a

1. Centro de Pesquisas Aggeu Magalhães da Fundação Oswaldo Cruz, Recife, PE. 2. Laboratório de Imunopatologia Keizo Asami da Universidade Federal de Pernambuco, Recife, PE. 3. Departamento de Medicina Tropical da Universidade Federal de Pernambuco, Recife, PE.

Endereço para correspondência: Dra Janaina Miranda. Depto ${ }^{\mathfrak{a}}$ de Biologia Celular e Ultra-Estrutura/CPqAM. Av. Moraes Rego s/n, Campus da UFPE, 50670-420 Recife, PE, Brasil

Tel: 5581 2101-2540; Fax: 5581 3453.2449.

e-mail: janamir@ cpqam.fiocruz.br

Recebido para publicação em 13/5/2003

Aceito em 1/11/2004 
outras espécies de filárias como Brugia malayi e Brugia pahangi. Acredita-se que a exposição de indivíduos a larvas infectantes possa estimular uma imunidade protetora, contudo, não existe um claro entendimento sobre 0 que ocasiona 0 aparecimento desta imunidade natural nas populações expostas à infecção filarial ${ }^{3}$.

Se a exposição é relativamente constante ao longo da vida, então o declínio da prevalência ou a diminuição da intensidade de infecção, em indivíduos de faixa etária mais elevada, pode indicar uma imunidade adquirida para larvas infectantes.

Na ausência de demonstrações empíricas, a existência da imunidade protetora na filariose humana tem sido objeto de intenso debate ${ }^{23}$. Alguns estudos sobre imunidade protetora têm sido descritos em gerbils, cães, ratos, gatos e macacos, por vacinação com larvas infectantes irradiadas de espécies de Brugia, porém 0 mecanismo responsável por essa imunidade ainda não está completamente elucidado ${ }^{28}$.

São poucos os trabalhos realizados sobre o reconhecimento antigênico por anticorpos de proteínas relevantes em extratos de larvas infectantes de W. bancrofti. Este fato, provavelmente, está relacionado à dificuldade em se obter material biológico em quantidade protéica suficiente. Alguns estudos de reconhecimento humoral em populações endêmicas de bancroftose, têm sido realizados utilizando-se extratos produzidos com larvas infectantes de B. pahangi, deixando, de certa maneira, o questionamento em relação à especificidade das reações ${ }^{378}$.

0 objetivo deste trabalho foi aprofundar os conhecimentos sobre a composição protéica de larvas de terceiro estádio sob 0 ponto de vista antigênico, assim como verificar que proteínas antigênicas podem ser reconhecidas pela resposta humoral em indivíduos de diferentes grupos clínicos de uma área endêmica.

\section{MATERIAL E MÉTODOS}

Estudo descritivo para pesquisa de microfilaremia. Indivíduos portadores de microfilaremia foram identificados durante a realização e um estudo descritivo para verificação da prevalência da doença na comunidade de Azeitona, bairro de Peixinhos - Olinda, Pernambuco. As residências foram escolhidas através de sorteio (amostra aleatória) e os respectivos moradores foram cadastrados através do preenchimento de uma ficha residencial pelo sistema porta a porta.

0 método diagnóstico utilizado foi 0 da gota espessa (GE) mensurada por punção de $60 \mu \mathrm{l}$ de sangue da extremidade digital. As lâminas foram coradas com hematoxilina pelo método de Carazzi e observadas em microscópio óptico com objetivas e oculares de 10x.

Considerações éticas. Este trabalho obteve a aprovação do Comitê de Ética em Pesquisa do Centro de Pesquisas Aggeu Magalhães/FIOCRUZ.

Classificação dos grupos de soros. As amostras de sangue foram coletadas por punção venosa de $10 \mathrm{ml}$ pelo sistema a vácuo. Todo o procedimento de campo foi realizado em horário noturno, entre 22:00 e 24:00h. Os voluntários participantes foram informados sobre a natureza da pesquisa e assinaram um termo de consentimento livre e esclarecido.
Foram formados quatro grupos de amostras de soros: i) Microfilarêmicos; ii) Crônicos: soro de indivíduos portadores de formas crônicas (elefantíase ou hidrocele); iii) Endêmicos normais: soro de indivíduos moradores da área endêmica, amicrofilarêmicos nos exames de filtração ( $5 \mathrm{ml}$ de sangue em membrana de $3 \mu \mathrm{m}$ de poro) e análise pela PCR com primer específico para W. bancroftiti ; iv) Controle negativo: soro de amicrofilarêmicos, moradores de área não endêmica. As amostras de soro dos grupos foram aliquotadas ( $50 \mu$ l de cada amostra de soro com as mesmas características clínicas) na forma de pool e assim empregadas na realização das reações imunoquímicas (Western-blot, imunofluorescência e dot-blot).

Obtenção de larvas infectantes. Foram utilizados mosquitos C. quinquefasciatus, linhagem de laboratório, originários de populações naturais de áreas urbanas do Recife. A infecção dos mosquitos foi obtida oferendo-se-lhes sangue parasitado (acima de 1.500 microfilárias por $\mathrm{ml}$ de sangue) em sistema de alimentação artificial através de membrana ${ }^{1}$. Um sistema de agitação do sangue no interior dos alimentadores proporcionou uma melhor distribuição de parasitas para a ingestão pelos insetos. Todos os insetos foram submetidos às mesmas condições de alimentação e ambientais de temperatura e umidade.

Produção dos extratos antigênicos. Para obtenção do antígeno secretório e excretório (AgSE) , aproximadamente 2.000 L3, foram incubadas em meio Hanks pH 7,2 (BioWhittaker) a $37^{\circ} \mathrm{C}$ com $5 \%$ de $\mathrm{CO}_{2}$, por 72 horas. Após centrifugação a $5.000 \mathrm{~g}$ por 10 minutos 0 sobrenadante foi filtrado em membrana estéril $(0,22 \mu \mathrm{m})$ e dializado ( Spectra/ Membrane MWCO: 6-8,000) contra PBS 0,01M pH 7,2 a 4ํㅡ durante 12 horas.

Por centrifugação a $5.000 \mathrm{~g}$ foram sedimentadas as larvas para preparação do extrato com proteínas solúveis em solução aquosa 0 sedimento parasitário foi congelado em nitrogênio líquido e quebrado em homogeinizador de tecidos de vidro esmerilhado, com PBS 0,01M pH 7,2 acrescido de inibidores de protease (TLCK 1mM; PMSF 1mM; e EDTA 1mM). Em seguida, foi ultrassonicado ( 5 ciclos de 30 segundos a 200W) e centrifugado a $25.000 \mathrm{~g}$ por 30 min a $4^{\circ} \mathrm{C}$. 0 sobrenadante obtido foi denominado AgS (Antígeno somático) e ao sedimento foi adicionado Tris 0,5M pH 8,3 acrescido de SDS a 1\% e Nonidet P-40 a 0,5\% para extração das proteínas solúveis por detergentes. Após centrifugação, o sobrenadante foi dializado (Spectra/ Membrane MWCO: 6-8,000) contra água destilada, durante 18 horas a $4^{\circ} \mathrm{C}$. Este extrato foi denominado AgSup.

Alguns mosquitos utilizados para extração das L3 foram macerados na presença de inibidores de protease, dos quais se obteve um extrato denominado AgCx (Antígeno de culex). Este extrato foi utilizado nas reações imunoquímicas, como controle, para verificar uma possível contaminação de proteínas oriunda da composição dos mosquitos. Todos os extratos produzidos foram liofilizados e congelados a $-20^{\circ} \mathrm{C}$ até 0 momento do uso.

0 teor protéico de todos os extratos produzidos foi dosado pelo Dye Reagent Concentrate ${ }^{5}$ (Micro Assay Protein - BIORAD). As medidas de absorbância foram feitas em espectrofotômetro (Beckman, Mod. DU-65 a um comprimento de onda de $595 \mathrm{~nm}$ ). 
Imunofluorescência. As larvas infectantes íntegras ( três larvas por campo) foram aderidas às lâminas e incubadas com $20 \mathrm{ml}$ de cada pool de soros de microfilarêmicos, portadores de forma crônica e amicrofilarêmicos de área não endêmica ( controle negativo) , na diluição de: 1:20; 1:50 e 1:100, em PBS $0,01 \mathrm{M} \mathrm{pH} 7,2$.

As lâminas foram deixadas a $37^{\circ} \mathrm{Cpor} 50$ minutos em câmara úmida e lavadas por 3 x 5 minutos em PBS 0,01M pH 7,2. Em seguida foram aplicados $20 \mu \mathrm{l}$ do conjugado IgG (anti-humano FITC) na diluição de 1:100 em PBS/Azul de Evans (1:10) e incubadas em câmara úmida a $37^{\circ} \mathrm{C}$ por 50 minutos. Após lavagens com PBS 0,01M pH 7,2, as lâminas foram secas e montadas com glicerina tamponada e lamínula e observadas em microscópio UV fluorescência com aumento de 40 vezes.

Dot-Blot. As reações de Dot-blot foram realizadas em discos de $0,6 \mathrm{~cm}$ de diâmetro de nitrocelulose (nitrato de celulose $0,45 \mu \mathrm{m}$ Advantec- Japão) como suporte. A cada disco foi aplicado 5ml de cada extrato (AgS, AgSup, AgSE e $\mathrm{AgCx})$, correspondendo a 25ng de proteína. Após 12 horas de incubação à temperatura ambiente, os discos foram lavados 2 vezes com PBS-Tween 0,05\% e incubados com leite desengordurado a $2 \%$ em PBS $0,01 \mathrm{M} \mathrm{pH} \mathrm{7,2} \mathrm{por} 2$ horas. Os quatro grupos de soro foram incubados por 1 hora a $37^{\circ} \mathrm{C}$, nas diluições de (1:20, 1:50 e 1:100) em tampão PBS 0,01M pH 7,2. 0 excesso de anticorpo não reagente foi retirado através de cinco lavagens em PBS-Tween 0,05\%.

Soro de cabra a-IgG humano conjugado à peroxidase (SIGMA) na diluição de 1:2.000 em PBS 0,01M pH 7,2 foi utilizado como segundo anticorpo com uma hora de incubação a $37^{\circ} \mathrm{C}$. A reação foi revelada com solução 0,05\% de 3,3 diaminobenzidina tetrahidrocloreto - DAB ( SIGMA) e interrompida com água destilada.

Western-Blot. Os extratos AgS, AgSE, AgSup e AgCx foram submetidos a eletroforese em gel de poliacrilamida SDS-PAGE unidimensional ${ }^{10}$ a $10 \%$. As amostras foram diluídas em tampão com b-mercaptoetanol na proporção de 2:1, e aquecidas a $95^{\circ} \mathrm{C}$ por cinco minutos. As eletroforeses foram

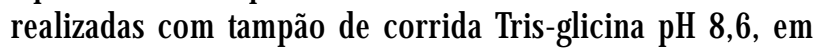
cuba de acrílico modelo mini protean II (BIORAD), sob uma corrente contínua de $20 \mathrm{~mA}$.

Os géis foram eletrotransferidos para membrana de nitrocelulose $0,45 \mu \mathrm{m}$, a uma corrente de $150 \mathrm{~mA}^{26}$. As tiras de nitrocelulose foram lavadas em PBS-Tween 0,05\% e incubadas por 18 horas com os respectivos pools de soros na diluição de 1:20 em PBS0,01 M pH 7,2. Como segundo anticorpo foi utilizado soro de cabra a-IgG humano conjugado com peroxidase (cadeia g específica), (SIGMA) e reveladas pelo 4-cloronaftol (SIGMA).

\section{RESULTAD0S}

Dados do estudo descritivo realizado durante a pesquisa de microfilaremia. Dos 840 indivíduos cadastrados, 792 (94,3\%) foram investigados e 87 (11\%) mostraram-se positivos. Adistribuição de microfilarêmicos em relação ao sexo não foi significativa ( $\mathrm{p}=0,809$ ) sendo 10,7\% (42 casos) para 0 masculino e 11,3\% ( 45 casos) para 0 feminino.

Os maiores (69\%) percentuais de positividade, se enquadram na faixa de baixa densidade parasitária de $1-60 \mathrm{mf} / 60 \mathrm{ml}$. No entanto, na faixa de alta densidade parasitária (> $120 \mathrm{mf} / 60 \mathrm{ml}$ ), 0 sexo masculino apresenta um maior número de casos (Tabela 1).

A faixa etária dos indivíduos pesquisados variou de 3 a 70 anos. Até aos 5 anos de idade foi identificado um único caso de positivo. As faixas de 11 a 19 anos e de 20 a 30 anos foram as mais populosas e de grande prevalência (Tabela 2).

Tabela 1 - Distribuição da carga parasitária, segundo o sexo.

\begin{tabular}{|c|c|c|c|c|c|c|}
\hline \multirow{3}{*}{$\begin{array}{l}\text { Densidade } \\
\text { (mf/60ml) }\end{array}$} & \multicolumn{4}{|c|}{ Sexo } & & \\
\hline & \multicolumn{2}{|c|}{ Masculino } & \multicolumn{2}{|c|}{ Feminino } & \multicolumn{2}{|c|}{ Total } \\
\hline & $\mathrm{n}^{0}$ & $\%$ & $\mathrm{n}^{0}$ & $\%$ & $\mathrm{n}^{0}$ & $\%$ \\
\hline $1-60$ & 30 & 66,7 & 30 & 71,4 & 60 & 69,0 \\
\hline $61-120$ & 11 & 24,4 & 5 & 11,9 & 16 & 18,4 \\
\hline$>120$ & 4 & 8,9 & 7 & 16,7 & 11 & 12,6 \\
\hline Total & 45 & 100,0 & 177 & 100,0 & 87 & 100,0 \\
\hline
\end{tabular}

Tabela 2 - Número de indivíduos portadores de microfilaremia, segundo a faixa etária.

\begin{tabular}{lrrr}
\hline Faixa etária (anos) & $\mathrm{n}^{0}$ & \multicolumn{2}{c}{ Positivos } \\
\cline { 3 - 4 } & & $\mathrm{n}^{0}$ & $\%$ \\
\hline $3-5$ & 23 & 1 & 4,3 \\
$6-10$ & 126 & 5 & 4,0 \\
$11-19$ & 254 & 32 & 12,6 \\
$20-30$ & 142 & 17 & 12,0 \\
$>30$ & 247 & 32 & 13,0 \\
\hline Total & 792 & 87 & 100 \\
\hline
\end{tabular}

Reação de Imunofluorescência indireta em superfície de larvas infectantes de W. bancrofti. Os soros de indivíduos microfilarêmicos reagem fortemente até a diluição de 1:100 com antígenos presentes na superfície das larvas infectantes dando fluorescência homogênea linear. Com os soros de portadores de forma crônica a reação foi fraca e somente até a diluição de 1:50. Não foi observada reação fluorescente com soro de indivíduos amicrofilarêmicos.

Reatividade dos soros com extratos antigênicos através de Dot-blot. Os soros de indivíduos microfilarêmicos reagiram com extratos AgS e AgSup até diluição de 1:100. Com portadores de forma crônica a reação foi obtida até a diluição de 1:50. A reação mais intensa ocorreu com o extrato AgSE com 0 soro de endêmicos normais diluído em até 1:100.

Perfil protéico dos extratos de larvas infectantes. Em SDS-PAGE as bandas evidenciadas no extrato AgSE após a revelação pelo método da prata foram de 175, 138, 105, 100, 76, 55, 49, 42, 39, 38, 32, $28 \mathrm{kDa}$. Os extratos AgS e AgSup, mostraram pelo mesmo método, duas únicas bandas de massa relativa de 49 e $55 \mathrm{kDa}$. 0 extrato $\mathrm{AgCx}$ apresentou bandas protéicas muito próximas e em grande quantidade, por isso não foram ilustrados seus valores em $\mathrm{kDa}$ (Figura 1). A concentração protéica de todos os extratos foi devidamente uniformizada para a aplicação no gel. 


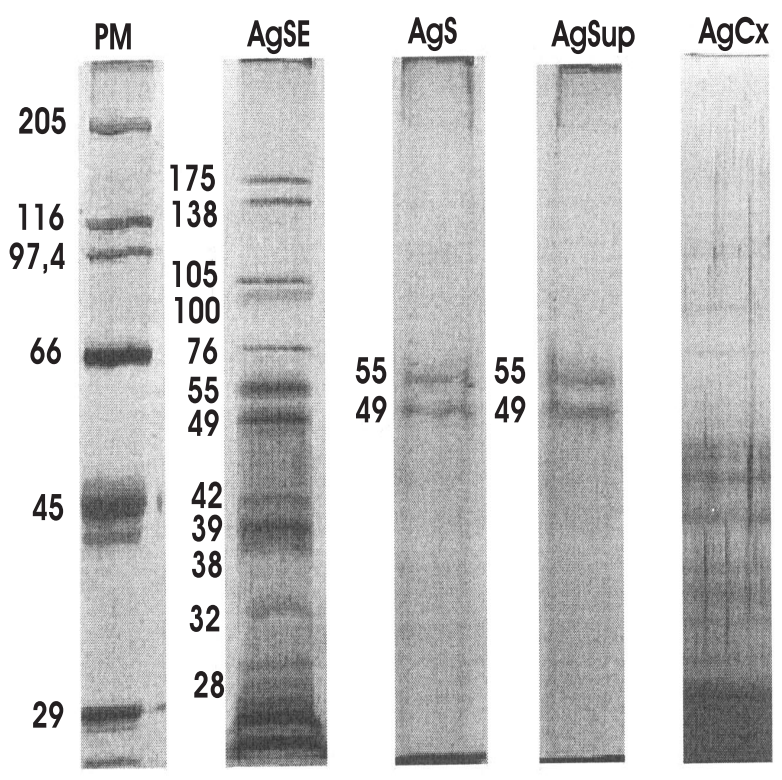

Kda

Figura 1 - Extratos antigênicos AgSE, AgS, AgSup. Separação por SDS-PAGE $10 \%$ unidimensional. Revelação por prata. AgCx colaboração por Commassie blue.

Reconhecimento antigênico nos extratos de larvas infectantes. As bandas protéicas de 49 e $55 \mathrm{kDa}$ dos extratos antigênicos AgS, AgSE e AgSup foram reconhecidas pelos soros de microfilarêmicos e de portadores de forma crônica (Figura 2) . Quando os soros de endêmicos normais reagiram com AgS houve 0 reconhecimento de bandas protéicas de

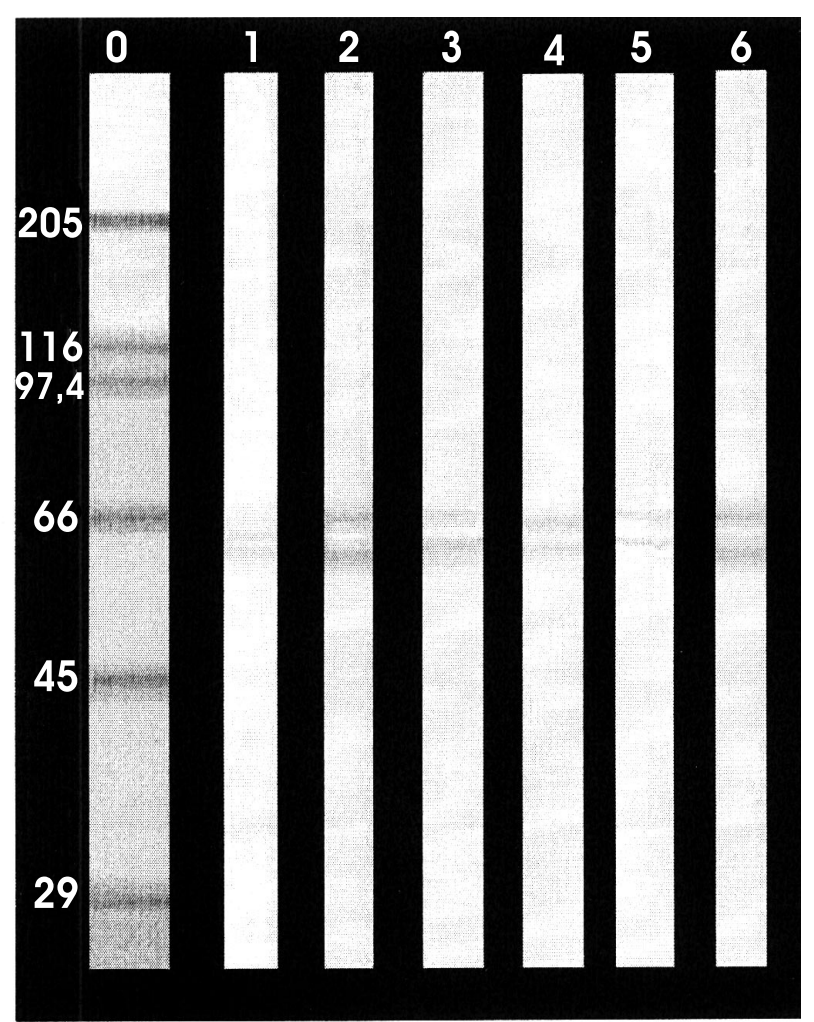

Figura 2 - Reacão de Western-blot em nitrocelulose. Revelação por 4-Cloronaftol. Padrão de peso modecular (a). Ags, soro de microfilarêmicos (1). Ags, soro de forma crônica (2). AgSE, soro de microfilarêmicos (3) AgSE, soro de forma crônica (4) AgSup, soro de microfilarêmicos (5). AgSup, soro de forma crônica (6).
100, 76, 55 e $49 \mathrm{kDa}$ e com AgSup das bandas de 49 e 55 $\mathrm{kDa}$. 0 soro de endêmicos normais no entanto, reconheceram no extrato AgSE um maior número de bandas (105, 100, 76, 55, 4939 e $34 \mathrm{kDa}$ ) (Figura 3). 0 extrato $\mathrm{AgCx}$ não foi reconhecido por nenhum dos três grupos de soros e 0 soro controle negativo não reconheceu nenhuma banda protéica nos extratos testados.

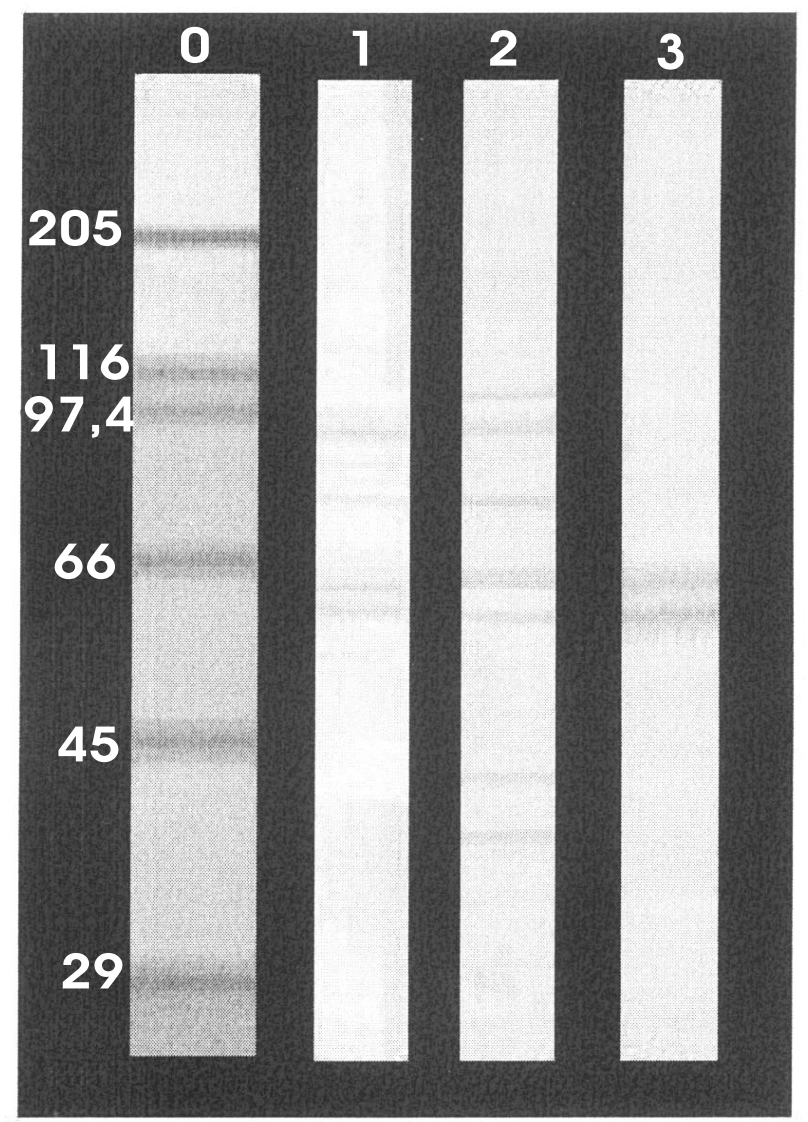

Figura 3 - Reação de Western-blot em nitrocelulose. Revelacão por 4-Cloronaftol. Padrão de peso modecular (a). Ags, endêmicos normais (1). AgSE, endêmicos normais, (2). AgSup, endêmicos normais.

\section{DISCUSSÃ0}

0 percentual (11\%) de microfilarêmicos encontrado neste trabalho confirma os dados de prevalência apresentados em inquéritos anteriores realizados no Município de Olinda ${ }^{13}$. De acordo com parâmetros da OMS, esses índices são considerados como de alta endemicidade ${ }^{29}{ }^{30}$. Considerando que 0 método

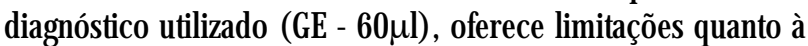
sensibilidade, podemos supor que estes valores devem estar subestimados.

Na faixa etária de 11 a 19 anos (independente do sexo), situam-se os índices mais altos (36,8\%) de microfilarêmicos. Inquéritos realizados anteriormente também mostram dados semelhantes ${ }^{21220}$. Adistribuição da positividade foi praticamente equivalente entre homens e mulheres $(10,7 \%, 11,3 \%$, respectivamente). Fato inusitado diante de dados da literatura onde se observa uma maior susceptibilidade à doença filarial 
em homens ${ }^{24630}$. Embora tenhamos encontrado carga parasitária acima de $120 \mathrm{mf} / \mathrm{ml}$ nos homens, podemos avaliar a população estudada como de baixa densidade parasitária, (69\% na faixa de $1-60 \mathrm{mf} / 60 \mu \mathrm{l})$, seguidos de $(61-120 \mathrm{mf} / 60 \mu \mathrm{l})$ em $18,4 \%$ de indivíduos. Estes dados são preocupantes uma vez que índices microfilarêmicos com estas densidades devem apresentar grande eficiência no processo de transmissibilidade ${ }^{24}$.

Em populações endêmicas expostas à infecção filarial, um grande espectro de resultados clínicos e parasitológicos são observados ${ }^{15}$. Este fato deve estar relacionado com 0 tipo e intensidade de resposta imune antifilarial ${ }^{19}$. Um grupo particularmente interessante neste contexto refere-se ao denominado endêmicos normais, indivíduos que apesar da constante exposição à doença são amicrofilarêmicos, assintomáticos e negativos para os testes de captura de antígenos circulantes. 0 estímulo à produção da imunidade protetora nesses indivíduos, seria decorrente da constante exposição ao parasito.

A existência da imunidade protetora em filariose humana permaneceainda, objeto de intenso debate ${ }^{9}$. Adesproporcionalidade de tamanho deste nematóide extracelular com relação às células imune efetoras do hospedeiro, além do grande período de convivência do verme nos linfáticos, leva ao questionamento da existência da imunidade protetora funcional em humanos. Contudo, a constatação de que somente um percentual de pessoas que vive em áreas endêmicas adquire a infecção filarial e de que existe um decréscimo idade-dependente na prevalência da infecção em comunidades endêmicas ${ }^{11}$, sugere que 0 desenvolvimento da imunidade protetora é uma realidade na filariose humana ${ }^{22}$. Esta constatação também tem sido demonstrada em trabalhos com modelos matemáticos aplicados em estudos epidemiológicos ${ }^{17}$ indicando a possibilidade da existência da imunidade protetora.

0 mecanismo pelo qual a larva infectante naturalmente migra através da circulação, atingindo os vasos linfáticos e a permanência do verme adulto por um longo período no organismo, faz com que exista interesse particular em determinantes antigênicos localizados na superfície da larva infectante. Pela técnica da imunofluorescência, os soros dos grupos de microfilarêmicos e portadores de forma crônica reagiram na superfície das larvas em padrão linear, porém observou-se uma intensa fluorescência na porção anterior, região bucal, da larva. Outros relatos já haviam mostrado a existência de epitopos antigênicos estágio específico na superfície de larvas infectantes, através da técnica de imunofluorescência e marcação radioativa ( Iodogen e Bolton-Hunter) ${ }^{14} 1618$.

0 extrato submetido à ação dos detergentes (AgSup), não demonstrou perfil diferente do AgS, sugerindo que as proteínas mais expressivas destas amostras são de constituição hidrossolúvel. Estes dados confirmam os observados por Maizels e Selkirk ${ }^{15}$. Estes autores verificaram que proteínas de superfície de Dirofilaria immitis de $35 \mathrm{kDa}$, e outras de 30-150 kDa de microfilárias de Brugia malayi, são hidrossolúveis e não requerem detergentes para sua liberação da epicutícula do parasito.

0 potencial antigênico dos extratos de larvas infectantes obtidos neste trabalho, foram validados com soros de indivíduos dos diferentes grupos estudados. Duas bandas proteicas de massa relativa de 49 e $55 \mathrm{kDa}$, mostraram-se imunodominantes, pois se apresentaram em todos os extratos testados (AgS, AgSup, AgSE).

Uma maior complexidade protéica, pode ser observada no extrato AgSE. Após a separação eletroforética, foram definidas doze bandas de massa relativa: 175, 138, 105, 100, 76, 55, 49, 42, 39, 38, 32, $28 \mathrm{kDa}$. Essas bandas protéicas devem estar associadas somente aos produtos liberados pelas larvas, uma vez que, não foi introduzido no meio de cultivo, nenhum nutriente proteico. Soros de endêmicos normais reconheceram em AgS, bandas protéicas de 100, 76, 55 e 49 kDa. A revelação das duas bandas de 100 e $76 \mathrm{kDa}$, demonstram grande sensibilidade nas reações imunológicas, desde que não foram visualizadas no gel após coloração com a prata.

Os resíduos orgânicos dos mosquitos, que poderiam apresentar contaminação, por conta da grande interação entre 0 parasita e 0 vetor, não foram identificados na reação comparativa entre os extratos AgSE e AgCx, que mostram no AgSE um reconhecimento de sete bandas 105, 100, 76, 55, 49, 39 e $32 \mathrm{kDa}$ na reação com soros de endêmicos normais, enquanto que $0 \mathrm{AgCx}$ embora apresente inúmeras bandas, essas não são reconhecidas pelos mesmos pools de soros.

0 estudo desses antígenos relevantes que são liberados, secretados ou excretados pelas larvas, tem sido restrito à descrição de peso molecular e reconhecimento imunológico. Estudos quanto à determinação da função biológica e atividade enzimática dessas macromoléculas merecem maior aprofundamento. 0 poder de clivagem proteolítica de IgG e outras imunoglobulinas podem estar associadas às enzimas secretadas por microfilárias de D. immitis ${ }^{2527}$. Substâncias como colagenases secretadas por Oncocerca e acetilcolinesterase secretados por espécies de Brugia tem sido descritas, contudo o papel dessas enzimas na infecção permanece especulativa $^{1521}$.

Estudos com antígenos secretórios e excretórios de larvas infectantes de W. bancrofti contribuirão para identificar os mecanismos que induzem a aquisição de imunidade protetora em indivíduos conhecidos como endêmicos normais.

\section{AGRADECIMENTOS}

ÀFACEPE pelo suporte financeiro e aos moradores e Agentes Comunitários de Saúde da Comunidade de Azeitona-Peixinhos, Olinda - PE.

\section{REFERÊNCIAS BIBLIOGRÁFICAS}

1. Albuquerque CMR, Neves JCM, Werkhäuser RP. Obtainment of Wuchereria bancrofti infective larvae (L3) from Culex quinquefasciatus (Diptera:Culicidae) using an artificial feeding technique. Memórias do Instituto Oswaldo Cruz 87: 593-595, 1992.

2. Albuquerque MFM, Marzochi MC, Sabroza PC, Braga MC, Padilha T, Silva MCM, Silva MRF, Schindler H, Maciel MA, Souza W, Furtado AF. Bancroftian filariasis in two urban areas of Recife, Brazil: pre-control observations on infection and disease. Transactions of the Royal Society of Tropical Medicine and Hygiene 89: 373-377, 1996. 
3. Bailey WJ, Hightower AW, Eberhard ML, Lammie PJ. Acquisitiond an expression of humoral reactivity to antigens of infective stages of filarial larvae. Parasite Immunology 17: 617-623, 1995.

4. Brabin L. Sex differences in susceptibility to lymphatic filariasis and implications for maternal child immunity. Journal of Epidemiology Infection 105: 335-353, 1990

5. Bradford MM. A rapid and sensitive method for the quantititation of microgram quantities of protein utilizing the principle of protein - Dye binding. Analytical Biochemistry 72: 248-254, 1976.

6. Bundy DAP. Sexual effects on parasite infections. Parasitology Today 4:186-189, 1988.

7. Day KP, Gregory WF, Maizels RM. Age-specific acquisition of immunity to infective larvae in a bancroftian filariasis endemic area of Papua New Guinea. Parasite Immunology 13: 277-290, 1991.

8. Helmy H, Weil GJ, Faris R, Gad AM, Chandrashekar R, Ashour A, Ramzy RMR. Human Antibody Responses to Wuchereria bancrofti infective larvae. Parasite Immunology 22: 89-96, 2000.

9. Kazura JW. Resistance to Infection with Lymphatic-dwelling filarial parasites. In: Nutman TB (ed) Lymphatic filariasis. Imperial College Press, p. 83-102, 2001.

10. Laemmili EK. Cleavage of structural protein during the assembly of the head of bacteriophage T4. Nature 227: 680-685, 1970.

11. Lammie PJ, Hightower AW, Eberhard ML (1994) Age-specific prevalence of antigenemia in a Wuchereria bancrofti-exposed population. American Journal of Tropical Medicine and Hygiene 51:348-355, 2002.

12. Maciel A, Rocha A, Marzochi KBF, Medeiros Z, Carvalho AB, Regis L, Souza W, Lapa T, Furtado A. Epidemiological study of bancroftian filariasis in Recife, Northeastern Brazil. Memórias Instituto Oswaldo Cruz 91 449-455, 1996.

13. Maciel A, Silva, E Rocha, A, Marzochi KB, Furtado A. Estudo comparativo de áreas endêmicas de filariose bancroftiana na Região Metropolitana do Recife, Brasil. Cadernos de Saúde Pública 10 (supl.2): 301-309, 1994.

14. Maizels R, Burke J, Sutanto I, Purnomo, Partono F. Secreted and surface antigens from larval stages of Wuchereria bancrofti, the major human lymphatic filarial parasite. Molecular and Biochemical Parasitology 19: 27-34, 1986.

15. Maizels R, Selkirk ME. Antigens of filarial parasites. ISI Atlas of Science 143-148, 1988.

16. Maizels RM, Partono F, Oemijati S, Denham DA, Ogilvie BM. Cross-reactive surface antigens on three stages of Brugia malayi, B. pahangi, and B. timori. Parasitology 87: 249-263, 1983.

17. Michael E, Bundy DAP. Herd immunity to filarial infection is a function of vector biting rate. Proceedings of The Royal Society of London Biological Sciences 265: 855-860, 1998

18. Ottesen EA. Infection and disease in lymphatic filariasis: an immunological perspective. Parasitology 104: S71-S79, 1992.
19. Piessens WF, Mcgreevy PB, Ratiwayanto S, Mcgreevy M, Piessens PW, Koiman I, Saroso J, Dennis DT. Immune responses in human infections with Brugia malayi: Correlation of cellular and humoral reaction to microfilarial antigens with clinical status. American Journal of Tropical Medicine and Hygiene 29: 563-570, 1980.

20. Rajagopalan PK, Das PK, Subramanian S, Vanamail P, Ramaiah KD. Bancroftian filariasis in Pondicherry, South India. Pre-control epidemiology observations. Epidemiology and Infection 103: 685-692, 1989.

21. Rathaur S, Robertson BD, Selkirk ME, Maizels RM. Secretory acetylcholinesterases from Brugia malayi adult and microfilarial parasites. Molecular And Biochemical Parasitology 26: 257-265, 1987.

22. Ravindran B, Satapathy AK, Sahoo PK, Babu Geddam JJ. Protective immunity in human bancroftian filariasis: inverse relationship between antibodies to microfilarial sheath and circulation filarial antigens. Parasite Immunology 22: 633-637, 2000.

23. Ravindran B, Satapathy AK, Sahoo PK, Mohanty MC Protective immunity in human lymphatic filariasis: problems and prospects. Medical Microbiology and Immunology 192: 41-46, 2003.

24. Southgate BA. The significance of low density microfilaremia in the transmission of lymphatic filarial parasites. Journal of Tropical of Medicine and Hygiene 95: 79-86, 1992.

25. Tamashiro WR, Scott AL. Proteolytic cleavage of IgG and other protein substrates by Dirofilaria immitis microfilarial enzymes. Journal of Parasitology 73: 149-154, 1987.

26. Towbin H, Staehelin T, Gordon J. Electrophoretic transfer of proteins from polyacrylamide gels to nitrocellulose sheets; procedure and some applications. Proceedings of the National Academy of Science 76: 4350-4354, 1979.

27. Vanamail P, Subramanian S, Das PK, Pana SP, Rajagopalan PK, Bundy DAP, Grenfell BT. Estimation of age-specific rates of acquisition and loss of Wuchereria bancrofti infection. Transactions of the Royal Society of Tropical Medicine and Hygiene 83: 689-693, 1989.

28. Wong MM, Guest FM. Filarial antibodies and eosinophilia in human subjects in an endemic area. Transactions of the Royal Society of Tropical Medicine and Hygiene 63: 769-800, 1969.

29. World Health Organization. Lymphatic filariasis infection \& disease: control strategies. Report of a WHO/CTD/TDR Consultative Meeting, held at the University Sains Malaysia, Penang, Malaysia 22-24, August, 1994.

30. World Health Organization. Lymphatic Filariasis: The disease and its control. Geneve, 1992.

31. Zhong M, McCarthy J, Bierwert l, Lizzotte-Waniewski MR, Chanteau S, Nutman TB, Ottesen EA, Williams SA. A PCR assay for detection of Wuchereria bancrofti in blood. American Journal of Tropical Medicine and Hygiene 54: 357-363, 1996. 